\title{
Justicia e impuestos. Comentarios a "La racionalidad de los impuestos" de F. Saffie
}

\author{
Justice and Taxes. Comments to "The \\ Rationality of Taxes" by F. Saffie
}

Hernán G. Bouvier*

Recepción: 25/02/20

Evaluación: 25/02/20

Aceptación final: 18/03/20

\begin{abstract}
Resumen: según el artículo principal existe en el derecho tributario un paradigma clásico que es deficiente. Saffie presenta un modelo alternativo basado en la idea de solidaridad y reconocimiento. El presente texto formula numerosas críticas tanto a la caracterización del paradigma clásico como al modelo alternativo. En especial se objeta la inclusión de varios autores en el paradigma clásico y las bases que supuestamente sostienen al modelo alternativo basado en la solidaridad y el reconocimiento.
\end{abstract}

Palabras clave: impuestos, justicia, reconocimiento

\begin{abstract}
: according to the main paper the classical paradigm of taxation is flawed. Saffie presents an alternative model based on the idea of recognition and solidarity. The present paper criticises the characterization of the classic paradigm and the alternative proposal as well. This paper challenges the
\end{abstract}

* Investigador adjunto, CONICET-UNC. Centro de Investigaciones Jurídicas y Sociales, Córdoba, Argentina. Correo electrónico: hernanbouvier@gmail.com 
inclusion of many authors in the classical paradigm and the grounds that allegedly support the alternative model based on solidarity and recognition. Key words: taxes, justice, recognition

\section{Introducción}

En "La racionalidad de los impuestos..." (de ahora en adelante, RDI) Francisco Saffie delimita lo que él llama paradigma clásico sobre los impuestos y aboga por un cambio de ese paradigma. El texto ofrece una serie de consideraciones tan sugerentes como creativas. En la sección 2 me limitaré a plantear algunas dudas sobre el alcance de algunos términos o conceptos generales como el de explicar, justificar y "dar cuenta". En la sección 3 plantearé mis dudas sobre la subsunción o inclusión de algunos autores en el llamado paradigma clásico instrumental. En la sección 4 me centraré en el paradigma que defiende Saffie y plantearé algunas dudas sobre la pertinencia o utilidad del aparato conceptual que usa en su apoyo. Se plantearán algunas dudas sobre la idea de bien interno, institución y práctica. En la sección 5 me limitaré a indicar algunos límites de la noción de reconocimiento tal cual viene presentada. Por último, en la sección 6 se presenta un posible problema del modelo propuesto por Saffie para evitar o solucionar casos de elusión. Tanto en la sección 5 como en la 6 propondré algunas aclaraciones complementarias que pueden ser útiles para una crítica posible del paradigma clásico. Estas últimas consideraciones también están dirigidas a que el autor se explaye sobre el trasfondo de su trabajo.

\section{Explicar, dar cuenta y justificar}

RDI pretende asumir dos tareas. Mostrar que las justificaciones que se dan en el derecho tributario desde el paradigma clásico son insuficientes y que las estrategias que se proponen para lograr la aplicación efectiva del derecho tributario son deficitarias. Se trata de dos niveles: uno de justificación y otro de aplicación. En sus palabras: 
Justicia e impuestos. Comentarios a "La racionalidad de los impuestos" de F. Saffie

Argumentaré que las soluciones propuestas [por el paradigma clásico] en estos dos niveles son inadecuadas porque no son capaces de dar cuenta de la racionalidad subyacente en el derecho tributario, puesto que se construyen a partir de justificaciones que contraponen intereses individuales con intereses colectivos aparejadas de justificaciones puramente instrumentales (tanto de los impuestos como del derecho tributario) (énfasis agregado)

Por su parte, el paradigma clásico, viene definido en los siguientes términos:

De acuerdo con el paradigma clásico, los impuestos solamente se justificarían si los individuos consienten en ellos porque van en su interés individual. En este sentido, los impuestos tienen una justificación instrumental: son medios para un fin que va en provecho de los miembros de la sociedad civil. Este paradigma clásico se construye sobre tres elementos: (i) los tributos se justificarían como instrumentos para la recaudación fiscal; (ii) bajo una concepción de los individuos como seres puramente racionales; y (iii) conforme a una concepción de la propiedad privada como derecho natural, opuesta a los tributos.

Por último, el paradigma clásico que no podría "dar cuenta de la racionalidad subyacente en el derecho tributario" atribuye una función determinada a los impuestos. Diversos autores que van desde Hobbes a Locke, pasando por Rawls, Nozick y Seligman concuerdan según Saffie en el carácter instrumental de estos impuestos (dirigidos al autointerés o recaudar para el gobierno o Estado).

Para comenzar -y concediendo por el momento la definición de paradigma clásico y los autores que lo representan- no parece haber aquí un déficit claro ni a nivel de explicación teórica ni a nivel de justificación. El problema surge con la expresión "dar cuenta” subrayada más arriba cuyo origen cercano puede ser la moda anglosajona de usar "give an account" para tres cuestiones diferentes: la explicación empírica, la explicación teórica, la justificación normativa. Voy a recorrer de manera rápida los sentidos en que se pueden usar esos términos porque eso servirá al propósito de la penúltima sección de este trabajo. Más allá de la utilidad relacionada con esta discusión 
las consideraciones que siguen pretenden colaborar con una tarea común y cooperativa de abandonar una terminología pegadiza pero equívoca.

El paradigma clásico - relacionado según RDI con el neoliberalismoes fácilmente explicable en términos empírico-sociales. De hecho, Saffie realiza una reconstrucción convincente sobre su origen filosófico, cómo se instaló a partir de los años 60 y 70 del siglo pasado y cuáles son sus efectos. No hay aquí misterio sobre la tesis explicativa empírica. Desde el punto de vista de la explicación teórica tampoco parece haber déficit alguno, aunque supone aclarar la connotación del término "explicación" en este contexto.

Existen tres sentidos usuales de "explicación" en términos teóricos. Estos tres sentidos se relacionan con el denominado análisis conceptual. El primero requiere descomponer un concepto en sus partes integrantes con el propósito o esperanza de proveer claridad conceptual (Erklärung). Aquí el concepto de explicación se vincula al concepto de explicitación. Se supone que "animal racional" es o era una buena explicación clarificadora del concepto de ser humano y otro tanto "figura de tres lados" para el concepto de triángulo. El segundo sentido de explicación teórica se vincula con tomar un concepto y relacionarlo con conceptos que aparecen junto a él de manera frecuente, nuevamente con la esperanza de otorgar claridad o precisión sobre la referencia del término o concepto analizado. Es posible intentar clarificar la noción de derecho privado aludiendo al concepto de contrato u horizontalidad y la noción de derecho público refiriendo a conceptos como ley o verticalidad (la idea es de Bobbio).

Se trata de la bien conocida explicación por conexión (Strawson). Por último, se "explica" un concepto o idea encontrando un mínimo común denominador, es decir, un concepto o propiedad básica común a todos los conceptos que estén bajo escrutinio. Es usual sostener a esta altura que el concepto o principio de daño "no da cuenta" o explica numerosas normas jurídicas penales porque existen sanciones para conductas que no dañan. Otro tanto para el concepto de sanción y su poder explicativo de las normas jurídicas, porque no todas las normas jurídicas amenazan con una sanción. Los diferentes sentidos de "explicación” y "dar cuenta" pueden multiplicarse ulteriormente, pero con lo dicho es suficiente por ahora.

Bien puede ser clarificador en términos explicativos para alguien que pregunta ¿qué es el impuesto? sostener que es aquello que se paga como 
Justicia e impuestos. Comentarios a "La racionalidad de los impuestos" de F. Saffie

contraprestación para sostener los gastos colectivos y estatales que van en su propio interés (o variantes de $i$-iii según la definición de RDI antes citada). No hay aquí un problema explicativo teórico. Lo que puede suceder con ese paradigma clásico es que uno no esté de acuerdo o le parezca mal. El paradigma clásico explica muy bien qué son y para qué están los impuestos bajo una cierta ideología. Es quizás la mejor explicación (clarificación) del concepto de impuestos para una concepción privatista y capitalista del uso del dinero y de la función del Estado. Capta muy bien el impuesto que permite pagar la seguridad, la pavimentación y la administración judicial que -si las cosas van bien- redunda en el interés de quien pregunta.

Existe una última variante -bastante equívoca- del término "dar cuenta" y "explicar” que lo equipara al término "justificar”. Es claro que RDI está cerca de este uso. Una teoría no da cuenta de un acto o institución porque no tiene buenos argumentos para justificarla normativamente. Esto es equivalente a decir que no ha encontrado o invocado una norma, razón o consideración ética o política válida para concluir lo que concluye. El paradigma clásico no da cuenta -en este sentido- de la "racionalidad subyacente" a los impuestos si y solo sí se acepta que la racionalidad subyacente a los impuestos es otra, lo cual es justamente el punto en discusión.

En resumen, y para cerrar este punto, la idea de no dar cuenta de un concepto admite múltiples usos. Dos centrales en RDI parecen ser el de explicación teórica y justificación, y toca escrutar en qué sentido el paradigma clásico no encuadra bien en la racionalidad subyacente en el derecho tributario. Las sugerentes consideraciones de Saffie Gatica parecen indicar más bien que las tres propiedades $i$-iii asociadas al paradigma clásico explican (clarifican/explicitan) muy bien qué tiene mente esa ideología, solo que esa ideología se equivoca con respecto a cómo deberíamos concebir los impuestos o -más frontalmente- por qué se debe tributar.

Si el paradigma clásico es defectuoso en su explicación teórica se debe mostrar algo que de manera más o menos intuitiva o compartida parece un impuesto o es designado como tal, pero no puede clarificarse apelando a $i$-iii (tal cual hacen los penalistas con el daño o los teóricos del derecho con la sanción). Si el problema es de justificación se debe mostrar con argumentos normativos (por pantanosos y provisorios que estos sean) que el paradigma clásico no está bien justificado o incurre en alguna contra- 
dicción o error fundamental. Sin embargo, desde mi perspectiva, RDI no hace eso. Más bien supone un modelo alternativo y lo explicita (aclara, expande, esquematiza) pero no indica con éxito por qué es superior normativamente. Regresaré sobre este punto en la penúltima sección. Por el momento cierro las consideraciones sobre el concepto de justificación y explicación.

Un problema ulterior se refiere a la inclusión de algunos autores en el paradigma clásico instrumental. Dedico la siguiente sección a problematizar una parte de ese ejercicio de clasificación.

\section{Los integrantes del paradigma clásico y la noción de impuestos como instrumentos}

El énfasis en RDI sobre el problema de la concepción "instrumental" de los impuestos parece motivarse no tanto por el hecho según el cual el diseño institucional que manda a pagar impuestos sirve a algún propósito, objetivo o fin. Es difícil concebir un diseño institucional cualquiera sin ver en él su servicio a algún fin. ${ }^{1}$ El problema no sería tanto concebir a los impuestos como instrumentos en el sentido de útiles o conducentes a algo, sino más bien en verlos como meros medios al servicio de una empresa autointeresada o -peor- al servicio de un fin o interés que las personas terminan percibiendo como meramente externo, ajeno. Por ejemplo, que solo sirve a un Estado o gobierno. No es del todo claro en el texto cómo se conjugan estas consideraciones con el tema de la justificación y aplicación de los impuestos. Quizás la idea vaya en la siguiente línea.

El paradigma clásico favorecería varias actitudes viciosas con impacto en la eficacia del derecho tributario y en el tipo de conductas de apego a la institución de referencia. Quizás la conjunción entre "los impuestos están justificados solo si me sirven" y "los impuestos son para el Estado"

1 De hecho, al usar Saffie una serie de consideraciones de MacIntyre sostiene que los impuestos deberían ser una práctica en la que podamos aprender acerca de las virtudes de la dependencia mutua. Esto concede alguna función o servicio instrumental a los tributos. Su punto crítico no puede ser que los impuestos pueden ser medios o instrumentos, sino cómo se concibe esa función o utilidad. 
Justicia e impuestos. Comentarios a "La racionalidad de los impuestos" de F. Saffie

generan en la ciudadanía una sinergia viciosa que, por un lado, fomenta el desarrollo de estrategias para no contribuir y, por el otro, genera un afecto de alienación frente al Estado. Una vez instalado este afecto de desapego, el Estado que recauda es visto como un mero depredador o apropiador de recursos "propios". De este modo, la visión instrumental, autointeresada, basada en la propiedad privada, socava el valor que debería encontrarse en los impuestos como medios de expresión y refuerzo de otros valores como la solidaridad.

En definitiva, los impuestos deben ser concebidos de otra manera. A saber: como la expresión de una virtud no privatista y altruista. Conjeturo, además -a partir de varios pasajes- que el autor considera que si tal concepción fuese eficaz (esto es, usada por ciudadanos y funcionarios) implicaría mayor apego a la práctica de pagar impuestos y decaería o bien el interés por buscar estrategias elusivas o bien la tolerancia judicial-administrativa frente a tales estrategias.

Si la lectura es correcta, el problema no es tanto aceptar que los impuestos son instrumentos, sino que se los conciba como meros instrumentos al servicio de individuos autointeresados o en provecho de un Estado percibido como lejano. Bajo la visión de Saffie, los impuestos no son meros instrumentos y además expresan (suponen, constituyen el ejercicio de) una virtud: la solidaridad. En otro texto del autor se realiza un énfasis semejante utilizando la terminología de la fraternidad. ${ }^{2}$ Cumplir con los impuestos expresa un acto de solidaridad o fraternidad que eventualmente puede ser instrumental a otros fines pero no se agota en ellos. Espero que estas consideraciones de lectura reconstruyan en parte el espíritu del texto. Por el momento no voy a objetar este cuadro. Más bien quiero plantear dudas sobre algunos de los autores que quedan incluidos en el paradigma clásico y meramente instrumental de los impuestos.

2 "los impuestos no son exclusivamente una fuente de financiamiento, sino que en su concepción política son manifestación de la fraternidad como principio rector de una organización social que considera en iguales términos la importancia de la esfera económica y política" (Saffie, 2012, p. 190). 
Tanto en RDI como en otro texto de Saffie, Rawls viene incluido en el paradigma clásico meramente instrumental. ${ }^{3}$ No puede negarse que Rawls concibe a los impuestos como un instrumento, el punto es si los concibe como meros instrumentos dirigidos al autointerés o a engrosar la recaudación estatal sin más.

No puede negarse que Rawls asigna a los impuestos una función instrumental de ajuste distributivo. Estos ajustes están movidos en gran parte por el principio de la diferencia o -más llanamente-por lograr que los que están peor estén algo mejor, con un cierto límite para tal cometido. No puede mejorarse a los que están peor con cualquier presión fiscal o a costa de la libertad (Rawls, 1999, p. 246). Un dato relevante es que adhiere a una estructura de los impuestos para la cual no es tan importante cuánto uno puede pagar o cuánto gana. Los impuestos deberían ser sensibles o corresponderse con cuánto ha tomado esa persona de los bienes de todos. La carga impositiva debe ser sensible a lo que uno utiliza de los bienes comunes (Rawls, 1999, p. 246) ${ }^{4}$. De igual manera es saliente en el Rawls tardío la insistencia en la relación entre el principio de la diferencia y la reciprocidad, al menos como la preocupación no autointeresada por el malestar de nuestros pares. Algún tipo de punto medio entre la imparcialidad y la ventaja mutua (Rawls, 2001). Surge una duda genuina sobre en qué sentido Rawls puede ser incluido sin más en una concepción meramente instrumental de los impuestos, basada simplemente en las características i-iii del paradigma clásico. ${ }^{5}$ Quizás su énfasis en la reciprocidad, la coopera-

3 “En 'Teoría de la Justicia' instituciones políticas como los impuestos, como veré más adelante, se justifican principalmente como instrumentos para la recaudación fiscal y no por su función política de justicia económica”. (Saffie, 2012, p. 188).

4 "[a expenditure tax] it is preferable to an income tax (of any kind) at the level of common sense precepts of justice, since it imposes a levy according to how much a person takes out of the common store of goods..." (Rawls, 1999, p. 246)

5 Un punto adicional que dejaría afuera del paradigma clásico a Rawls es su concepción sobre la propiedad privada. Pero se trata de un tema complicado en su teoría. En Justice as Fairness se indica que la propiedad personal es un derecho básico. Esto no excluye que la dinámica institucional pueda restringir lo que usualmente se llama propiedad privada. Eventualmente podría acordarse - siguiendo los principios de la justicia y teniendo en cuenta las circunstancias históricas o la estabilidad - modos de propiedad compatibles con alguna forma del socialismo en sentido amplio. La justicia como equidad no implica necesariamente, ni excluye a priori, la propiedad privada o la colectivización de los medios de producción. La sociali- 
Justicia e impuestos. Comentarios a "La racionalidad de los impuestos" de F. Saffie

ción mutua, el sentido de justicia y conceptos semejantes no sea suficiente para incluirlo en el paradigma que defiende Saffie en RDI, pero ciertamente es dudoso que forme parte del paradigma clásico. En todo caso sería interesante ver qué puede agregar Saffie como muestra de que Rawls se encuentra en el paradigma clásico instrumental que satisface $i$-iii. Es interesante conocer en qué sentido la idea de Rawls de reciprocidad es lejana u opuesta a la idea de solidaridad y fraternidad. Quizás exista un tercero no excluido entre el paradigma clásico y el paradigma que defiende RDI.

Un problema de clasificación semejante surge para Holmes y Sunstein y su bien conocido libro El costo de los derechos: por qué la libertad depende de los impuestos. Según RDI, el libro es una muestra de cómo la noción instrumental ha permeado todos los argumentos posibles a favor de los impuestos. En la nota 11 de RDI se sostiene

Según ellos, todo derecho (negativo o positivo) implica que el Estado debe invertir cierta cantidad de dinero en su protección, o, como lo ponen ellos, "los derechos cuestan dinero". Desde la perspectiva defendida por Holmes y Sunstein, todo derecho es un derecho positivo mientras exija alguna acción de parte de alguien para su protección y exigibilidad.

Nuevamente, sostener que los impuestos son instrumentos no es equivalente a sostener que los impuestos son meros instrumentos en el sentido del paradigma clásico. Varias citas del texto de Holmes y Sunstein ponen en duda que pueda ser incluido sin más en el paradigma clásico. No supeditan los impuestos a una mera cuestión económica individualista y resaltan repetidas veces la relación estrecha entre impuestos y cooperación. Las siguientes citas son bastante elocuentes (Holmes, S. \& Sunstein, Cass R, 2011)

El hecho de que los costos de ese orden, indispensable para la protección de los derechos básicos deban ser cubiertos por los contribuyentes tiene una significación teórica además de financiera:

zación de los medios de producción podría ser adoptada si se muestra que es la forma más eficiente de cumplir con los principios de la justicia. (Rawls, 2001, pp. 114, 177). Además, rechaza cuanto menos el capitalismo del estado de bienestar (p. 135 y ss.). 
Hernán G. Bouvier

destacan la dependencia esencial del individualismo basado en los derechos de la acción del Estado y de la cooperación social (p. 106)

Las finanzas públicas constituyen una ciencia ética porque nos obligan a llevar cuentas públicamente de los sacrificios que como comunidad decidimos hacer y a qué estamos dispuestos a renunciar para alcanzar metas más importantes (p. 120)

Por supuesto que eso no quiere decir que los derechos deban ser arrojados, junto con todo lo demás, a una gigantesca calculadora de costo-beneficio creada y manejada por economistas (p.124)

$\mathrm{Al}$ ser instrumentos para el mejoramiento del bienestar individual y colectivo, los derechos naturalmente requieren diversas clases de renuncias de todos los miembros de la comunidad... renuncias que deberían ser abundantemente compensadas por los beneficios que derivan de la reciprocidad, la especialización y la suma de esfuerzos (p.201)

Una sociedad justa intenta garantizar oportunidades razonables para todos y también asegurar que nadie caiga por debajo de un umbral decente. Esto es parte de lo que expresa la idea central liberal que entiende a la sociedad como una empresa cooperativa (p. 214)

...los derechos de propiedad representan una aplicación selectiva de recursos públicos no solo con el fin de estimular la autolimitación por todas partes... sino también para impulsar nuevas formas de actividad creativa, tanto del gobierno como el individuo... (p.217)

Los derechos de los ciudadanos estadounidenses son artificios que la comunidad crea y mantiene con el objeto de mejorar la calidad de vida colectiva e individual (p. 238)

Existen en el texto de Holmes y Sunstein, claro está, varias indicaciones sobre algunos de los fines que pueden cumplir los impuestos dirigidos al bienestar. Entre ellos, lograr las condiciones mínimas para que uno pueda valerse por sí mismo ("autoayuda”). La forma en que viene modelado el valor de la "autoayuda" y cómo los impuestos contribuyen a ello no supone una apología del individualismo. Solo una lectura rápida del libro puede tomar el término "autoayuda" como valerse por uno mismo sin dependencia. Los autores son claros al decir que una sociedad de bienestar liberal debe proveer para que las personas puedan valerse por sí mismas 
(el ejemplo paradigmático es la educación pública). Sin embargo, sería exagerado decir que están exacerbando una idea de individualismo que desconoce la cooperación mutua y sumergida que implica cualquier logro "personal" (véase, p. 225, 227, 232). Por el contrario, tratan de mostrar que aquello que para el norteamericano medio es "mi derecho" y "mi logro" depende de una cooperación colectiva impresionante. El énfasis en lograr la "autoayuda" no debe ser leído como "ud. todo lo puede y no debe nada a nadie" sino como la búsqueda de autonomía, la cual nunca implica un logro absolutamente individual. Según las palabras de Sunstein y Holmes: "la Carta de Derechos es un 'hágalo Ud. mismo' que los ciudadanos sólo pueden obtener en tiendas financiadas por los contribuyentes" (p. 225). Las libertades suponen depender de otros y sufrir restricciones. Nada de eso puede lograrse sin contribuir.

Quizás las citas indicadas, en donde se relativiza el individualismo y se subraya la cooperación, no sean suficientes para convencer a Saffie de que Holmes y Sunstein están de su lado, pero resulta exagerado sostener que están sin más en el paradigma clásico según se lo definió. Para ellos el autointerés no es todo, la propiedad privada depende de la cooperación conjunta y los logros y derechos individuales no existirían sin un esfuerzo colectivo. Tal vez las citas textuales indicadas puedan servir para ubicar a Holmes y Sunstein en otro tercero no excluido entre el paradigma clásico y el modelo de la solidaridad y reconocimiento propuesto en RDI.

Cierro aquí las consideraciones sobre el alcance del paradigma clásico meramente instrumental de los impuestos y las dudas sobre los autores que caen bajo esa clasificación. En la sección siguiente me ocupo de la propuesta alternativa de Saffie.

\section{Prácticas, bien interno e instituciones}

En la sección 5 de RDI se ofrece el modelo alternativo al paradigma clásico instrumental, no sin antes pasar por consideraciones algo borrosas sobre substancia y forma. Si entiendo bien, la distinción está dirigida a mostrar que mientras no se cambie el modo en que se concibe a los impuestos de nada servirá apelar a principios o tener en cuenta la intención del Parla- 
mento o variantes que van en la línea de honrar el espíritu de la ley. La clave para este cambio según el texto radica en entender al derecho tributario como "la forma institucional de una práctica con un bien interno: el reconocimiento recíproco".

Para mostrar la plausibilidad de su propuesta Saffie apela a consideraciones de MacIntyre y Honneth.

La idea básica es que hay una práctica que no es equivalente a la institución que la realiza o pretende realizarla. Las instituciones pueden incluso frustrar esa práctica o mancillarla. El problema general que surge aquí es con el concepto de práctica virtuosa que la institución puede reforzar o marchitar. En especial porque la práctica sería algo diferente de la institución.

Si se entiende "práctica" como la de pagar impuestos o semejantes, no hay práctica sin institución. No es claro cuál sería la práctica no institucional que tiene un valor que hay que seguir. Puede ser quizás la de ser solidario, aunque no existan los impuestos. En ese caso, la idea es que hay una práctica genérica de reconocimiento y solidaridad que la institución de los impuestos debe reflejar. No es la práctica de los impuestos, es algo que puede existir sin impuestos, y que los impuestos realizan. El texto a veces oscila entre el valor de la práctica sin institución y el valor de la institución de pagar impuestos que a todas luces parece una práctica que no puede existir sin institución. Es posible continuar pese a esta duda y adentrarse en los autores que usa Saffie en su provecho. Tomo tres citas de RDI sobre MacIntyre para plantear algunas dudas y luego me ocupo en la sección siguiente del rendimiento de Honneth para lo que se pretende defender.

Dos ejes de MacIntyre son centrales para Saffie. La distinción bienes externos/internos y la distinción entre prácticas/instituciones.

Según la definición de "bien interno" ellos (a) solamente pueden ser especificados por referencia a la práctica de la cual forman parte; y (b) solo pueden identificarse y reconocerse participando en la práctica en cuestión. ${ }^{6}$

6 "Las prácticas con bienes internos requieren de participación en ellas, para que así la persona que participa llegue a aprender el bien dentro de la práctica. La manera en que compartimos ciertos estándares y propósitos que caracterizan a las prácticas, define la manera en que nos relacionamos unos con otros" (RDI, sección 5) 
Justicia e impuestos. Comentarios a "La racionalidad de los impuestos" de F. Saffie

La noción de bienes internos así presentada es indistinguible de la noción de participación en una práctica para comprender ciertos conceptos (o bromas) y no aporta demasiado desde el punto de vista normativo. No es relevante que un comunitarista aggiornado agregue, de manera persuasiva, que esos son bienes "genuinos", porque eso no es más que decir que son bienes para la práctica misma y que solo se entienden si uno está en la práctica. Por lo demás, es posible imaginar alguien que defienda el paradigma clásico alegando que Ud. captará el bien cuando se entregue a la práctica sin resistencias. Es decir: cuando juegue al juego varias veces y de la manera que pretende el autointeresado maximizador. Es un problema habitual de las propuestas que apelan a un bien o valor interno -entendido como tener un punto de vista que uno capta solo si está inmerso en ella -que o bien presuponen lo que hay que probar, o bien funcionan como instrumento rápido de exclusión de argumentos. Esto es así en la medida en que se puede contestar que el otro no está viendo el punto porque no participa. Como en muchas de estas propuestas participar supone usar y/o aceptar la regla, la práctica o la institución, una de dos: o bien uno participa y no acepta (no ve como "bien genuino" eso que se dice bueno) pero entonces en realidad no está participando, o bien participa aceptando lo cual excluye la posibilidad de objetar esos supuestos bienes. Las discusiones sobre la fe, la gracia, el don y la iluminación tienen muchas veces este contenido.

Hasta aquí, entonces, dos problemas: el primero es que la caracterización es idéntica a cualquier caracterización que requiere (para la comprensión de un concepto por ejemplo) la inmersión en la práctica; el segundo es que otorga un instrumento argumental a cualquiera de las partes. Estos dos problemas se conjugan para dar lugar a un tercero. Si hay bienes internos, puede haber males internos (lo cuales también requieren a y b, según supongo) así que eso solo no sirve para mostrar en qué consiste ese bien "genuino" o por qué es un bien. Se necesita más. Tengo mis dudas entonces sobre qué puede aportar la utilización de MacIntyre a la idea de Saffie. Estas dudas no concluyen con el uso de bien interno y/o genuino. Continúan con dos aspectos más.

En efecto, además del par interno/externo, Saffie se pliega a una definición bastante circunscripta de institución presente en MacIntyre. Aquella que acerca la idea de institución a su rasgo competitivo y amenazante de 
Hernán G. Bouvier

la práctica que sustenta. Las citas relevantes son las siguientes, todas de la sección 5 de RDI.

La segunda diferencia es respecto de las instituciones. MacIntyre sostiene que las prácticas son diferentes y no deben confundirse con éstas. Según MacIntyre, las prácticas se refieren a bienes internos y las instituciones, a bienes externos. Esta es una diferencia fuerte, toda vez que MacIntyre establece que las instituciones se relacionan "necesariamente" con los bienes externos, tales como el dinero u otros bienes materiales y la distribución del poder [...] las instituciones están necesariamente conectadas a los bienes externos porque ellas son las "sustentadoras" de las prácticas. Para poder sostenerse en el tiempo, las prácticas requieren de las instituciones. En esta estrecha relación radica también un riesgo. Las prácticas pueden sucumbir a "la codicia de la institución, donde la atención cooperativa al bien común de la práctica es siempre vulnerable a la competitividad de la institución.

En primer lugar, cabe señalar un disenso menor. No se ve por qué habría que acercar la institución a la competencia. Salvo un uso restrictivo y estipulativo del término. Algo más central es que esta tesis parece inscribirse en aquella que sospecha de la técnica y de los artificios en general como mecanismos que manchan, denostan, ensucian, degradan un "afuera" (para este caso, las prácticas) que tienen un valor en sí. Suspira aquí una larga tradición política que ve a las instituciones como mecanismos tendencialmente espurios e intoxicantes de un espacio que tiene su valor y sentido en sí mismo sin intervención institucional. ${ }^{7}$

7 Existe una larga tradición que concibe a la sociedad, el lenguaje escrito, la técnica y las instituciones, como algo que vendría a degradar un ámbito de sentido autónomo, completo y genuino. Esta cosmovisión de la decadencia o mancha del estado puro se encuentra en la teoría del lenguaje según la cual el signo escrito sería una versión menor de una idea o significado que está por detrás del signo y no depende de él. También en las versiones de la lingüística para las cuales puede haber sentido sin formulación o para las cuales la palabra representa imperfectamente el pensamiento o el alma. Se repite en visiones antropológicas para las cuales las comunidades más o menos aisladas se habrían visto intoxicadas por la adopción de la inscripción, representación y otras técnicas del lenguaje. Derrida muestra cómo existe un paradigma de pensamiento que, desconfiando de la técnica, la inscripción, 
Justicia e impuestos. Comentarios a "La racionalidad de los impuestos" de F. Saffie

Indicar que las instituciones implican competencia o que tendencialmente degradan las prácticas no es el problema mayor del uso de MacIntyre. Más central todavía es el ejemplo mismo que se usa para graficar la familiaridad con un bien interno. En términos de Saffie

Se le podría ofrecer dinero al niño para comprar caramelos, a fin de motivarlo a jugar primero y luego para que continúe, cada vez que gane en el juego. El profesor espera que el niño adquiera un "gusto" por el juego, para que acabe jugando no por el dinero (para comprar caramelos), sino por amor al ajedrez. En este ejemplo, el dinero y los caramelos son bienes externos respecto de los bienes internos del ajedrez, y el niño podría buscar adquirirlos incluso mediante trampas. Sin embargo, la expectativa del profesor es que, con el tiempo, el bien que hay en jugar ajedrez se mostrará y realizará, de manera que el niño llegará a jugar ajedrez porque le gusta. Las prácticas con bienes internos requieren de participación en ellas, para que así la persona que participa llegue a aprender el bien dentro de la práctica.

Según la presentación, recibir dinero o caramelos no forman parte del bien interno de la práctica, pero el niño podría entender la práctica y el bien interno empezando a jugar por otras razones. Aquí se concede que los motivos y razones por los cuales se ingresa en una práctica pueden ser ajenos al bien de la práctica lo que no impide que se adquiera la virtud (supuesta). Esto no puede funcionar en contra del paradigma clásico y menos a favor del paradigma de Saffie.

Si pagar impuestos ya tiene como "razón subyacente" o "substancia" la solidaridad o fraternidad, la actitud autointeresada y mezquina tenderá a disolverse (o eso se supone, porque la evidencia parece mostrar lo contrario para el pago de impuestos). En todo caso, da igual lo que mayormente se crea sobre la práctica o la institución. Sometidos a la repetición del juego

la escritura, la sociedad y su organización, supone un afuera (una "autenticidad social") que cualquier sofisticación instrumental vendría a manchar determinando su "decadencia” o imperfección. Esta forma de ver el mundo atraviesa a Platón, Aristóteles, Saussure, Rousseau, Levi-Strauss, entre otros (Derrida, 2003). 
de pagar impuestos, entenderemos que el bien substantivo y genuino no son los caramelos de la evasión sino los confites de la solidaridad. No me es claro si se trata de una tesis de sicología social mezclada con ética. Es decir, una tesis que conjetura sobre lo que surgirá en la conciencia de las personas cuando entren al juego que -por hipótesis-ya tiene una sustancia diferente a la que declara el paradigma clásico. La pregunta directa aquí es: si el juego ya tiene esa sustancia -fraternal solidaria- y se puede aprender el bien genuino incluso ingresando por las razones incorrectas ¿qué más hay que hacer? ¿Se trata además de intervenir mientras juegan "concientizando"? ¿Algo así como una pedagogía social en que se enseñe a los participantes que esto no es por los caramelos? No se trata de preguntas retóricas sino de entender qué más hay que hacer si el juego ya tiene la sustancia y bien interno que incluso puede llegar a captar quien ingresa por razones externas. En todo caso, el ejemplo del ajedrez dejaría incólume a los que defienden el paradigma clásico dado que se concede que se puede entrar a jugar por razones externas (léase, espurias).

Se puede sostener que, aunque se ingrese por razones espurias habrá que intervenir de alguna manera para que se adquiera la actitud correcta porque en caso contrario la práctica se corromperá o el bien interno se apagará. Sostener que si se ingresa por las razones "externas" ello llevará a una debacle de la práctica es más una tesis pesimista que una prueba de la tesis ético-sociológica sobre qué pasa cuando permanecemos en una práctica con cierta actitud. También es cierto que hay prácticas e instituciones que bien pueden pervivir incluso cuando los participantes siguen jugando cada uno por sus motivos o razones, con la sola condición de que sus conductas se conformen a las reglas. Y por supuesto, hay mucha prueba empírica de gente que entra en una práctica (¿o institución?) por las razones “incorrectas" y luego ve lo que supuestamente es valioso en esa práctica.

En resumen, la noción de bien interno de MacIntyre no demuestra que la solidaridad-reconocimiento sea el bien "genuino" de la práctica (o la institución), lo supone. Por su parte, se pliega a una noción de las instituciones como amenazantes de las prácticas y concede que a esas prácticas que tendrían un bien genuino que las instituciones pueden amenazar se puede ingresar por cualquier razón espúrea y luego quizás se verá el bien interno. Esto deja inmutable a quien sea que defienda el paradigma clásico. Salvo 
Justicia e impuestos. Comentarios a "La racionalidad de los impuestos" de F. Saffie

que se diga que lo que tiene que suceder es que cuando esté en la práctica deberá empezar a "jugar" por las razones correctas, que hasta el momento son las "genuinas", que son las que define la práctica misma, que supuestamente dependen de su substancia que no es ni debe ser la del autointerés instrumental y privatista. No se ve, en consecuencia, cómo este armamento teórico trae razones a favor del modelo de la solidaridad y reconocimiento. Y no queda claro, como se planteó en las preguntas anteriores, qué más se requiere durante el juego con bien interno para que los participantes absorban o capten el bien interno que la práctica supuestamente ya tiene. Quizás se esté pensando en algún proyecto pedagógico masivo. ${ }^{8}$

En realidad, el argumento final de Saffie no depende de la distinción interno/externo, ni el de institución vs. práctica. Depende de la idea según la cual el bien que puede traer el ejercicio de pagar impuestos (se lo caratule de interno o externo, genuino o no) "requiere una noción más compleja de los individuos en las sociedades modernas contemporáneas que la del paradigma clásico, que sea capaz de combinar los elementos individuales y sociales que los caracterizan”. Quizás aquí radica para Saffie el elemento deficitario del paradigma clásico. O bien no sería una buena explicación teórica de una práctica compleja que no puede clarificarse solo apelando a individuos, o bien es una mala justificación. El paradigma clásico no da cuenta de los impuestos en el sentido de que estos se aplican con independencia de los intereses individuales (aspecto explicativo teórico) y no puede justificarse solo apelando a elementos individuales. Si este es el defecto explicativo o justificativo del paradigma, es una hipótesis más que algo que surja claramente del texto. Seguramente una breve aclaración de Saffie puede servir para disipar estas dudas.

Como sea, el texto supone que su paradigma es superior al clásico. Creo que lo supone, como intentaré mostrar, sobre bases insuficientes.

8 Un indicio en esta línea es la siguiente afirmación: "La segunda gran reforma que necesitamos es una que puede partir en las escuelas de derecho y que debería materializarse pronto en la práctica jurídica tributaria: revisar qué significa, que supone, cumplir con la ley tributaria. Esto puede dar lugar a reformas legales que vayan contra la planificación, la elusión y la evasión tributaria" (Saffie, 2012 , p. 191). 
Hernán G. Bouvier

\section{Reconocimiento y explicación}

La teoría de Honneth basada en Hegel sería superior a teorías individualistas porque indica qué necesita una persona para formarse como tal y ser autónoma. Una vez más aparece el elusivo concepto de explicación. Saffie se propone "primero, mostrar cómo es que, de acuerdo con estas teorías, la interacción con otros individuos explica la manera por medio de la cual podemos llegar a ser sujetos autónomos" (énfasis agregado).

Que el reconocimiento mutuo sea aquello que explica (posibilita) que seamos autónomos no es una prueba de que los impuestos son mejor concebidos como un acto de reconocimiento. Con suerte deja en claro cómo y por qué surgen individuos con autonomía y deja implícito o supuesto que aquello que garantiza la autonomía es valioso. Pero del hecho que el reconocimiento sea la condición de posibilidad de llegar a ser autónomos no se sigue que los impuestos sean o deban ser parte de esa práctica. O en todo caso hay que explicitar qué tipo de reconocimiento se puede legítimamente reclamar. También está probado que una persona que no ha recibido el afecto amoroso y corporal suficiente durante la infancia, es decir, que no ha recibido un apego afectivo suficiente, arriesga el autismo, la esquizofrenia o es arrojado sin más a una vida triste y gris. El apego (y también la interdicción) son la condición de posibilidad de una cierta integridad subjetiva. Eso no es suficiente para mostrar que los impuestos deberían ser entendidos como honrando el apego afectivo o corporal, ni mucho menos valida la conclusión según la cual dado que eso es valioso allá (en el crecimiento y la maduración) es valioso aquí. No puedo exigir, por ejemplo, que en el trato institucional se me de afecto y cercanía indicando tan solo que eso es relevante en otro ámbito o esfera personal o política. Incluso concediendo que el reconocimiento explica cómo se llega a ser alguien autónomo, eso no es suficiente para mostrar que tal tipo de reconocimiento (por demás difuso) deba seguir en pie como expectativa mutua para cualquier otro tipo de interrelación social o institucional. No puedo esperar que el presidente o la rectora me abrace, aunque sea cierto que sin abrazos en el momento indicado el daño a mi conformación personal habría sido irreparable.

Aquello que identifica las condiciones de posibilidad de una capacidad que se considera valiosa, es decir, aquello que deja en claro las condiciones 
Justicia e impuestos. Comentarios a "La racionalidad de los impuestos" de F. Saffie

necesarias para que podamos ejercer algo como la autonomía, no tiene por qué justificar la expectativa normativa en cualquier otra esfera.

No obstante, los argumentos de Saffie no culminan aquí. Luego de analizar diferentes sentidos de reconocimiento (fundamental en este aspecto la distinción que cita de Siep), considera que el reconocimiento forma parte de la práctica y bien interno de los impuestos. En sus palabras

Las esferas de reconocimiento que más estrechamente se relacionan con las prácticas y las instituciones son las del derecho y de la solidaridad. Por tanto, si estamos buscando una justificación de la tributación como práctica bajo este esquema, entonces necesitamos encontrar el bien que hay en la práctica (lo que proporcionará los fundamentos para que la práctica se convierta en una institución).

Como ya se ha indicado, buscar un bien interno a la práctica no nos compromete por sí solo con aceptar que el bien de la práctica sea el reconocimiento mutuo. Buscar un bien interno a la práctica no excluye ciertos contenidos normativos. Es por eso por lo que se indicó que las ideas de Saffie no necesitan -hasta donde se alcanza a ver- usar el aparato de bien interno y externo. Lo que necesitan es mostrar que hay algunos bienes que no valen la pena ser perseguidos y que los impuestos pueden formar parte de lo que merece buscarse.

Aunque RDI hace surgir las dudas planteadas hasta ahora, también se impone reconocer que el déficit teórico y justificativo del paradigma clásico está al alcance de la mano si se profundizaran algunas de las sugerencias del texto. Esto implica mostrar el defecto de explicación o el defecto de justificación más allá de suponerlo. RDI otorga incentivos al respecto y más de una pista. Existen algunos planteos básicos para objetar la explicación y la justificación del paradigma clásico. Sin estos planteos, el modelo de la fraternidad y la solidaridad se encuentra incompleto.

Uno está sugerido en el otro texto de Saffie citado aquí. Según sus palabras: "Pero los impuestos no solo son una fuente de financiamiento del gasto público, de hecho el Estado, en principio, tiene varias otras formas de asegurar los recursos que necesita" (Saffie, 2012, p. 190).

Esta breve consideración muestra la punta de un ovillo cuyo desarrollo puede llevar a una refutación de una explicación teórica. En efecto, para 
quien caracteriza todo aquello que normalmente se llama "impuestos" como el instrumento para financiar el Estado basta mostrarle que hay cosas que se llaman impuestos y no financian el gasto del Estado y que hay gastos que el Estado podría financiar sin impuestos. Saffie no indica cómo esto puede suceder, pero supongo que está pensando en que el Estado mantenga - por ejemplo- el monopolio sobre empresas que generan riquezas a partir de bienes comunes o algún otro medio alternativo de enriquecimiento sin tributación lisa y llana. Se trata de un gesto teórico explicativo dirigido a mostrar que la supuesta propiedad definitoria o común de la extensión del concepto no es necesaria ni suficiente.

Quedan a disposición dos estrategias más. Estas suponen aceptar que una explicación teórica o una justificación es deficiente si incurre en un sinsentido o contradicción. Una explicación teórica es deficitaria si incurre en una contradicción pues se supone que entonces no racionaliza el concepto bajo análisis. Una justificación es defectuosa si parte de una contradicción porque una contradicción justifica cualquier contenido normativo (o ninguno).

Es obvio que actualmente se pagan costos que parecen a todas luces "impuestos" o así vienen llamados y que no van en el interés individual de quien paga, así que una explicación teórica en esos términos no capta la extensión, uso o alcance del concepto que está analizando y una de las características asociadas al concepto es contradictoria con su extensión. Hay impuestos sin satisfacción de autointerés. Es bien conocida la salida a este problema, sobre todo para quien sea que se encuentre dentro del paradigma clásico. La primera es conceder que son impuestos, aunque son injustos, la segunda consiste en sostener que dado que son injustos no son "verdaderos" impuestos. No queda más salida parece que caer en los créditos de una justificación normativa de fondo y ver si conduce a algún tipo de contradicción o sinsentido.

El paradigma clásico, según viene presentado, anida tres contradicciones que no surgen a primera vista. Mejor dicho, ellas surgen bajo una interpretación posible de i-iii o, lo que es equivalente, bajo un mayor detalle. Estas contradicciones son de carácter pragmático, en el sentido usual de que suponen aceptar una consideración o la realización de una acción que implica una segunda o tercera, y estas últimas están en contradicción con la primera. 
Justicia e impuestos. Comentarios a "La racionalidad de los impuestos" de F. Saffie

Algún integrante del paradigma clásico podría sostener que es injusto que le cobren este o aquel impuesto y realizar este reclamo con pretensiones de objetividad. Bajo la asunción de que algo es justo solo si satisface el autointerés, en conjunción con la asunción de que el Estado es un conjunto de individuos (o asociación) con eficacia decisoria, la expresión "los impuestos que cobra el Estado son o pueden ser injustos" puede resultar contradictoria o analíticamente vacía. Es contradictoria si el pago de esos impuestos va en el autointerés de los que integran el Estado (funcionarios, empleados y profesionales de la política). No puede ser injusta si va en el interés de alguien, por definición.

La contradicción pragmática surge si hay un reclamo de justicia objetivo ("está mal") usando un criterio relativista o subjetivo. El contenido de "injusto" puede ser reducido al autointerés al precio de aceptar que hay varias cosas justas e injustas al mismo tiempo o -lo que es equivalentesostener que la justicia es relativa. Por supuesto, no todo integrante del paradigma clásico tiene por qué incurrir en la contradicción de anhelar la justicia objetiva mientras concede que la justicia es relativa a los intereses y que hay alguien interesado que se está beneficiando (p.ej. los funcionarios estatales). Si lo hace, y permanece en su reclamo de justicia, deberá encontrar un argumento que desplace las pretensiones normativas más allá de la frontera definida en términos de autointerés lo que suele abrir la puerta para la justicia como imparcialidad. ${ }^{9}$

Un problema semejante surge si la cláusula del autointerés en el paradigma clásico es entendida a modo de condición necesaria para empezar a pagar impuestos o como justificación para dejar de pagar impuestos (generalmente sazonada con la afirmación de que no se paga impuestos porque el Estado "no me da nada"). Para que el Estado o cualquier otra "asociación" pueda brindar algún beneficio (incluso individual), alguien debe pagar. Si

9 No hay nada que "ofrecer" o "reclamar" en términos de justicia si lo justo viene concebido en términos de autointerés y una de las partes no puede perder o ganar nada y además puede retirarse de la cooperación. Es decir, si cuenta con la ventaja de amenaza. Si lo que se reclama está más allá de la frontera de negociación definida en términos de autointerés, debe introducirse alguna consideración ulterior según la cual algo puede ser justo aunque no beneficie o satisfaga la utilidad individual de los participantes en el conflicto o discusión. Sobre los límites de la justicia y negociación en contextos de autointerés (Barry, 2001, cap. I). 
todos los jugadores adoptan la actitud de no pagar hasta que lleguen los beneficios, o no pagar hasta que los otros lo hagan, el juego se paraliza a sí mismo. No es posible obtener un beneficio que depende de la "colaboración" si todos los participantes adoptan la actitud de no colaborar hasta que llegue el beneficio. Se trata de una paralización autoinfligida porque el juego presidido con esa actitud (es decir, permitiendo esa actitud) no podría empezar nunca. El ejemplo más obvio es el de dos jugadores de tenis enfrentados que adoptan a rajatabla la misma regla: no saco hasta que saques tú.

El pago no puede esperar al beneficio, sino que el beneficio depende del pago. Esa actitud imposibilita la práctica incluso en sus propios términos. Nuevamente, esta tensión solo se da si se sofistica el paradigma clásico y se asume o comprueba esa actitud frente a la práctica impositiva.

La tercera variante, bien conocida, es apelar a la importancia de la propiedad privada para eludir o evadir impuestos. Nos movemos aquí al terreno de la aplicación o deber de aplicación de los impuestos con espíritu privatista. Este afecto privatista puede adquirir varias modulaciones. No todas ellas abrigan una tensión o contradicción. Una que sí lo hace es la siguiente: negarse a pagar cualquier impuesto invocando la propiedad privada y el mercado que la posibilita desconoce que no hay propiedad privada ni mercado sin una institución que provee monitoreo y ejecutabilidad (lo cual suele hacer la forma "Estado") ${ }^{10}$. Desfinanciar a quien provee monitoreo y ejecutabilidad hará subir los costos de transacción y oportunidad hasta límites ineficientes.

No pagar impuestos puede ser un tiro en la bota privatista en la medida en que la evasión impide que la protección de la propiedad privada y el mercado sean garantizados como se debe. Bajo estas asunciones el mismo acto elusivo o evasor para proteger la propiedad privada, la amenaza. En una versión posible supone aceptar dos contenidos normativos parcialmente contradictorios: la permisión y prohibición de afectar la propiedad privada.

Estos son los elementos necesarios y quizás suficientes para dar por deficitario al paradigma clásico en su versión de explicación teórica o en su versión de justificación. No "da cuenta" de la extensión de la aplicación

10 Sobre la relevancia del monitoreo y ejecutabilidad para el mercado y la propiedad privada: North, 1990. 
del concepto, porque se llaman impuestos a diseños institucionales que no van en el interés de quien debe pagar y "no da cuenta" en el sentido de que no puede justificar -sin incurrir en contradicciones pragmáticas- cuándo está justificado pagar y cuándo no.

Con estos aditamentos se encuentra la vía para explorar concepciones alternativas de los impuestos y el derecho tributario. La del reconocimiento y solidaridad propuesta por Saffie resulta promisoria. A esta empresa la espera en las cercanías una objeción que sortear. La indico de manera escueta en la sección que sigue.

\section{Elusión y desprecio}

Munidos del espíritu de la solidaridad y el reconocimiento recíproco podríamos solucionar el problema de la elusión. Es decir, las estrategias ocurrentes para que la conducta se conforme a un régimen tributario más benigno sin caer en la evasión. Casos típicos de elusión que pretenden ser captados como evasión son el del matrimonio para pagar menos impuestos, o declarar el auto nuevísimo como perteneciente a la empresa o sociedad para luego poder descargarlos como inversión en la empresa evitando la carga por adquisición de bienes personales. No es para nada claro si existe algún diseño normativo y de principios que pueda terminar con estas estrategias cuya maldad hay que probar más allá de la antipatía personal que nos generen. Las dificultades cabalgan sobre el lomo de la distinción entre conformarse a una regla o cumplirla (conform vs. comply).

Conjeturo que adoptando los conceptos propuestos en RDI lo que sucedería es que conductas que ahora son elusivas y permitidas, pasarían a ser consideradas evasivas y prohibidas. Se trataría de una consecuencia interpretativa de tomar de otra manera los textos jurídicos disponibles o los por venir.

El problema central y cercano que se avizora es el siguiente: supóngase que bajo una interpretación "clásica", "textual", "privatista", "restringida" una norma no capta una conducta y que a pesar de eso una autoridad judicial indica que se ha infringido una ley. Supongamos, porque la ley tiene como razón subyacente el espíritu solidario y no se detendrá ante tecnicismos 
formalistas como el del alcance de los términos. El problema que surgiría para el modelo alternativo de Saffie consiste en justificar por qué serán tratados como casos de evasión casos que son de elusión (o como prohibidos aquellos que parecen permitidos). Más puntualmente, por qué atrapar al vivillo que se conformó a lo que indica el texto de la ley no supone un caso de desprecio. La sorpresa en la libertad y el patrimonio son una forma paradigmática del desprecio al otro como sujeto autónomo en la medida en que no permite prepararse o decidir con todos los hechos, normas y razones sobre la mesa. El modelo del reconocimiento tiene que mostrar cómo es posible atrapar a un contribuyente elusivo, que conformó su conducta al texto legal y público, sin despreciarlo en el sentido especificado.

\section{Bibliografía}

Barry, B. (2001). Teorías de la Justicia. Barcelona: Gedisa.

Derrida, J (2003). De la gramatología. Buenos Aires: Siglo XXI.

Holmes, S. y Sunstein, C.R. (2011). El costo de los derechos: por qué la libertad depende de los impuestos. Buenos Aires: Siglo XXI.

North, D. (1990). Institutions, Institutional Change and Economic Performance. Cambridge: Cambridge University Press.

Rawls, J. (1999). A Theory of Justice. Revised Edition. Cambridge: Harvard University Press.

Rawls, J. (2001). Justice as Fairness. A Restatement. Cambridge: Harvard University Press.

Saffie, F. (2012). De la reciprocidad solo a la fraternidad. Derecho y Humanidades (19), 179-191. 